\title{
Performance Evaluation of a Novel Hydro - Pneumatic Suspension System of a Heavy Truck on Ride Comfort
}

\author{
Le Xuan Long ${ }^{1}$, Dang Viet $\mathrm{Ha}^{2}$, Le Van Quynh ${ }^{1 *}$, Bui Van Cuong ${ }^{1}$, and Vu Thi Hien ${ }^{1}$ \\ ${ }^{1}$ Faculty of Automotive and Power Machinery Engineering, Thai Nguyen University of Technology, Thai Nguyen, \\ Vietnam \\ ${ }^{2}$ Vietnam Register, Ha Noi 12059, Viet Nam
}

\begin{abstract}
The purpose of this work is to evaluate the performance of novel hydrfo-pneumatic suspension system (HPSs) in comparison with traditional hydro-pneumatic fsuspension system (HPSs) of a heavy truck in the direction of improving vehicle ride comfort. Firstly, the nonlinear dynamic models of the traditional and novel HPS systems are set up to determine the vertical forces. And then, the vertical forces are connected with a 3-D nonlinear dynamic model of heavy truck with 10 degrees of freedom under random excitation of road surface. The root mean square (RMS) acceleration responses of the vertical cab, pitch and roll angles of the cab $\left(\mathrm{a}_{\mathrm{wzcb}}, \mathrm{a}_{\mathrm{wfcb}}\right.$ and $\left.\mathrm{a}_{\mathrm{wtcb}}\right)$ based on the International Standard ISO 2631-1: 1997 are chosen as objective functions. The study results show that the $\mathrm{a}_{\mathrm{wzcb}}, \mathrm{a}_{\mathrm{wfcb}}$ and $\mathrm{a}_{\mathrm{wtcb}}$ values with novel HPSs reduce by $28.27 \%, 28.32 \%$ and $6.89 \%$ in comparison with traditional HPSs when vehicle moves on ISO class D road surface at vehicle speed of $50 \mathrm{~km} / \mathrm{h}$ and full load. Finally, the ride performance of novel HPSs is verified and compared and evaluated with traditional HPSs under different operating conditions and the evaluation results are also indicated that the ride performance of a novel HPSs is better than the traditional HPSs under survey conditions.
\end{abstract}

\section{Introduction}

Hydro-pneumatic suspension systems (HPS) are used more and more widely on heavy truck due to their advantages. Heavy trucks often operate in mine areas where the road surface conditions are not good, so improving the ride comfort of vehicles is always interested in research. Due to the viscous resistance of the fluid and the compressibility of gas the damping and stiffness coefficient of the HPS are adjusted when vehicles operate with different conditions. Research to improve the performance of HPS has been studied many scientists. The nonlinear factors of the HPS were considered to improve the precise determination the height of the HPS in the process control [1]. The effects of hydro-pneumatic parameters on the ride safety and aid with design optimization and tuning of the suspension system were investigated based on the cosimulation environment, the vehicle multi body dynamics (MBD) model and the road model [2]. A multi-cylinder hydro-pneumatic suspension system was proposed and analyzed their design parameters based on an inplane multi-body dynamics (MBD) model and road model [3]. The effect of various suspension parameters on storage stiffness and damping coefficient of a dual-chamber hydro-pneumatic suspension was analyzed using numerical simulation [4]. A Hydro-Pneumatic (HP) suspension system interconnected for load sharing in heavy vehicles was analyzed based on the nonlinear mathematical model of a three-axle heavy vehicle [5]. The parameter optimization of the hydro-pneumatic suspension was found out to obtain the minimum root mean square of vertical accelerations under different driving conditions based on the multi body model of the wheel loader [6]. The damping force property of the hydro-pneumatic suspension system under different fractional orders was proposed and analyzed using a hydropneumatic suspension model based on fractional order [7]. A novel suspension configuration with both hydraulically interconnected suspension and electronic controlled air spring was proposed and controlled through the height of the elastic part using a fuzzy controller based on a 9-degree-of-freedom vehicle multi-body model [8]. The semi-active hydro-pneumatic suspension proposed and controlled by fuzzy controller [12].

This study proposes a novel HPSs which is developed the traditional HPS by connecting a main air chamber and an auxiliary air chamber through the surge pipe which has more the elasticity of gas and nonlinear viscous damper and the friction damper of the air in the surge pipe for controlling the nonlinear stiffness and damping coefficients of the novel HPS when vehicle operates under the different conditions. Firstly, the nonlinear dynamic models of the traditional and novel HPS systems are set up to determine the vertical forces. And then, a 3-D nonlinear dynamic model of heavy truck with 10 degrees of freedom (DOFs) is set up under random road surface roughness according to ISO 8608(1995) [9].

*Corresponding author: lequynh@tnut.edu.vn 
The root mean square (RMS) acceleration responses of the vertical cabin, pitch and roll angles of the cab ( $a_{w z c b}$, $a_{w f c b}$ and $\mathrm{a}_{\mathrm{wtcb}}$ ) based on the International Standard ISO 2631-1: 1997 [11] are chosen as objective functions. Finally, the ride performance of the novel HPSs is evaluated and compared to the traditional HPSs under different operating conditions.

\section{Model of hydro-pneumatic suspension systems}

In the traditional HPSs, the stiffness force of the suspension system is formed by the elasticity of air chamber and the damping force of the suspension system is formed by the viscous of the oil through the orifice of combined piston. In addition to the same characteristics of traditional HPS, in the novel HPS, the stiffness coefficient of the suspension system is formed more by the elasticity of air in surge pipe and reservoir and the damping is created more by the nonlinear viscous damper and the friction damper of the air in the surge pipe. The structural diagrams of the traditional and novel HPS are shown in Fig 1. The mathematical models are set up based on the structural diagram of Fig 2.

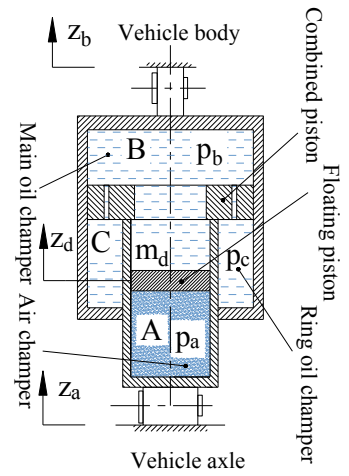

(a) Traditional HPS

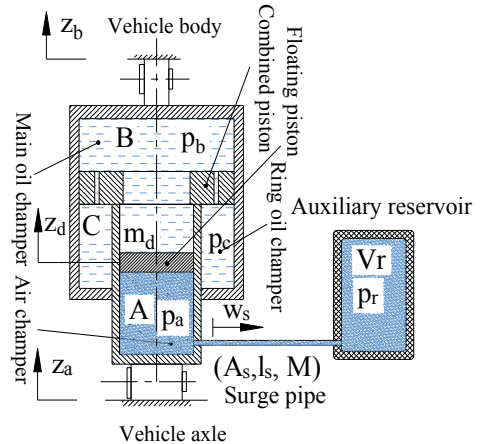

(b) Novel HPS

Fig 1. Structure models of HPS

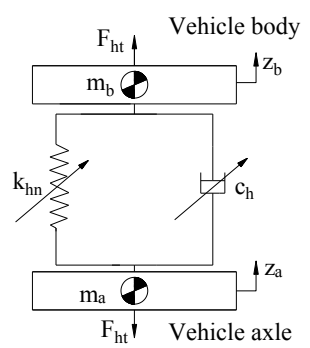

(a) Traditional HPS

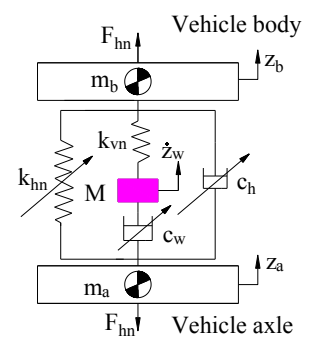

(b) Novel HPS

Fig 2. Mathematical models of HPS

\subsection{The vertical dynamic force of the traditional HPS}

From Fig 2(a), the vertical dynamic force of the traditional HPS could be defined as

$$
F_{h}=F_{k}+F_{c}
$$

Where, $F_{k}$ and $F_{c}$ are the elastic and damping force of the traditional HPS

The elastic force $\left(\mathrm{F}_{\mathrm{k}}\right)$ of the traditional HPS is formed by the compressive property of the gas in air chamber which is calculated based on the laws of thermodynamics method.

$$
F_{k}=\left(p_{a}-p_{0}\right) A_{p}
$$

The pressure in air chamber is defined as an adiabatic process following the laws of thermodynamics

$$
p_{0} V_{0}^{n}=p_{a} V_{a}^{n}
$$

Where, $\mathrm{p}_{0}$ and $\mathrm{V}_{0}$ are the initial absolute pressure and volume in air chamber, $\mathrm{p}_{\mathrm{a}}$ and $\mathrm{V}_{\mathrm{a}}$ are the absolute pressure and volume in air chamber, $\mathrm{n}$ is the polytrophic rate $(1<\mathrm{n}<1.4)$. 


$$
p_{a}=p_{0}\left(\frac{V_{0}}{V_{a}}\right)^{n}, V_{a}=V_{0}+A_{p}\left(z_{b}-z_{a}\right)
$$

Combination of Eq. (2) and Eq. (4), the elastic force of the gas chamber of the traditional HPS is determined as

$$
F_{k}=p_{0}\left(\frac{V_{0}}{V_{0}+A_{p}\left(z_{b}-z_{a}\right)}-1\right) A_{p}
$$

The damping force $\left(\mathrm{F}_{\mathrm{c}}\right)$ of the traditional HPS is formed by the viscous of the oil through the orifice of combined piston. It can be calculated as

$$
F_{c}=p_{b}\left(A_{b}-A_{p}\right)-p_{c}\left(A_{b}-A_{c}\right)-\left(p_{0}-\frac{m_{d} g}{A_{p}}\right)\left(A_{c}-A_{p}\right)
$$

where, $A_{b}, A_{c}$, and $A_{p}$ are the area of cylinder, rod and floating piston, $p_{b}$ and $p_{c}$ are pressure in the main and ring oil chamber.

The flow rate through the orifice is calculated as

$$
Q=C_{d} A \sqrt{2 \frac{\left(p_{c}-p_{b}\right)}{\rho} \operatorname{sign}\left(\dot{z}_{b}-\dot{z}_{a}\right)}
$$

where, $C_{d}$ is coefficient of discharge, $A$ is the area of the orifice, cylinder and floating piston and $\rho$ is the density of oil. On the basic of volume balance, the flow rate is inferred as

$$
Q=\left(A_{b}-A_{c}\right)\left(\dot{z}_{b}-\dot{z}_{a}\right)
$$

From Eq. (7) and Eq. (8), the relationship $\mathrm{p}_{1}$ and $\mathrm{p}_{2}$ is determined as

$$
p_{c}=p_{b}+\frac{\rho\left(A_{b}-A_{c}\right)^{2}\left|\dot{\mathrm{z}}_{b}-\dot{\mathrm{z}}_{a}\right|\left(\dot{\mathrm{z}}_{b}-\dot{\mathrm{z}}_{a}\right)}{2 C_{d}^{2} A^{2}}
$$

The differential motion equation of floating piston can be defined as

$$
\left(p_{b}-p_{a}\right) A_{p}-m_{d} g=m_{d} \ddot{z}_{d}
$$

Combination of Eq. (6), Eq. (9) and Eq. (10), the damping force is computed as

$$
\begin{aligned}
& F_{c}=-\frac{\rho\left(A_{b}-A_{c}\right)^{3}\left|\dot{\mathrm{z}}_{b}-\dot{\mathrm{z}}_{a}\right|\left(\dot{\mathrm{z}}_{b}-\dot{\mathrm{z}}_{a}\right)}{2 C_{d}^{2} A^{2}} \\
& +p_{0}\left(A_{c}-A_{p}\right)\left(\left(\frac{V_{0}}{V_{0}+A_{p}\left(z_{b}-z_{a}\right)}\right)^{n}-1\right)-\frac{m_{d} \ddot{z}_{d}}{A_{p}}\left(A_{c}-A_{p}\right)
\end{aligned}
$$

\subsection{The vertical dynamic force of the novel HPS}

Due to the influence of the nonlinear viscous damper, friction damper and the elasticity of the air in the surge pipe, the elastic and the damping force of the novel HPS is changed in comparison with traditional HPS. The vertical dynamic force of novel HPS $\left(F_{h n}\right)$ could be determined as

$$
F_{h n}=F_{k n}+F_{c n}
$$

Where, $F_{\mathrm{kn}}, \mathrm{F}_{\mathrm{cn}}$ are the elastic and damping force of the novel HPS

The elasticity of the gas in air chamber, the reservoir and surge pipe create the elastic force of the novel HPS. The elastic force of the novel HPS is defined as

$$
F_{k n}=K_{e}\left(z_{d}-z_{a}\right)+K_{v}\left(z_{d}-z_{a}-w_{s}\right)
$$

where, the static, viscous stiffness constants $\left(K_{e}, K_{v}\right)$ and the mass $(M)[14,15]$ could be calculated as:

$$
K_{e}=\frac{p_{0} A_{p}^{2} n}{V_{0}+V_{r 0}}, K_{v}=\frac{p_{0} A_{p}^{2} n}{V_{0}+V_{r 0}} \frac{V_{r 0}}{V_{0}}, M=A_{s} l_{s} \rho_{a}\left(\frac{A_{p}}{A_{s}} \frac{V_{r 0}}{V_{0}+V_{r 0}}\right)^{2}
$$

where, $\mathrm{n}$ is the polytropic rate $(1<\mathrm{n}<1.4) ; p_{0}$ is the initial absolute pressure in air chamber; $\rho_{a}$ is the air density; $V_{0}$ and $V_{r 0}$ are initial volume of air chamber and reservoir.

The model parameter $C_{z \beta}$ is related to the velocity over the damper and not like $C_{s}$ to the velocity in the surge pipe. The vertical viscous force is written as

The Eq. (15) can be rewritten as

$$
F_{v z}=K_{v}\left(z_{d}-z_{a}-w_{s}\right)=C_{z \beta}\left|\dot{w}_{s}\right|^{\beta} \operatorname{sign}\left(\dot{w}_{s}\right)+M \ddot{w}_{s}
$$

$$
M \ddot{w}_{s}=K_{v}\left(z_{d}-z_{a}-w_{s}\right)-C_{z \beta}\left|\dot{w}_{s}\right|^{\beta} \operatorname{sign}\left(\dot{w}_{s}\right)
$$

The relationship between the nonlinear damping $C_{z \beta}$ and the damping $c_{s}$ caused by the flow in the surge pipe is defined:

$$
C_{z \beta}=C_{s}\left(\frac{A_{p}}{A_{s}} \frac{V_{r 0}}{V_{0}+V_{r 0}}\right)^{1+\beta}, C_{s}=\frac{1}{2} \rho A_{s} C_{s t}=\frac{1}{2} \rho_{a} A_{s}\left(C_{f r}+C_{e n}+C_{c}+C_{b}\right)
$$

Where, $C_{s t}$ is total loss coefficient, $\mathrm{C}_{f r}, \mathrm{C}_{e}, C_{c}, C_{b}$ are the loss coefficient due to friction, enlargement, contraction and bends in the pipe, $\beta$ is viscous damping parameter.

The damping force $\left(\mathrm{F}_{\mathrm{cn}}\right)$ is determined by the Eq. (6) where, the pressure in air chamber is calculated as 


$$
p_{a}=\frac{F_{k n}}{A_{p}}
$$

\section{Full-Vehicle dynamic model}

\subsection{The motion equation of vehicle model}

A structural diagram of a heavy truck is shown Fig.3 which consist of front and rear axles, vehicle body, cab, four hydro-pneumatic suspension struts of vehicle and four isolation systems of cab. A three-dimensional vehicle-road coupled dynamic model of a heavy vehicle (a mining dump truck) with 10 degrees of freedom under random road surface roughness is set up to analyze the effectiveness of HPSs compared to the traditional HPS in the direction of the ride comfort of vehicle, as shown in Fig.3., which consists of the tire stiffness and damping coefficients $\mathrm{k}_{\mathrm{ti}}$ and $\mathrm{c}_{\mathrm{ti}}$, the stiffness and damping coefficients of HPSs $k_{i}$ and $c_{i}$, the stiffness and damping coefficients of cab isolation system $k_{\mathrm{ci}}$ and $\mathrm{c}_{\mathrm{ci}}$, the vertical displacements of front axle, rear axle, vehicle body, cab, $\mathrm{z}_{\mathrm{a} 1}, \mathrm{z}_{1}, \mathrm{z}_{2}, \mathrm{z}_{\mathrm{b}}$ and $\mathrm{z}_{\mathrm{c}}$, the angular displacements of axles, vehicle and cab bodies, $\theta_{\mathrm{a} 1}, \theta_{\mathrm{a} 2}, \varphi_{\mathrm{b}}, \theta_{\mathrm{b}}$ and $\varphi_{\mathrm{c}}, \theta_{\mathrm{c}}$, the inertia moments of axle, vehicle and cab masses $I_{a x 1}, I_{a x 2}, I_{b x}, I_{b y}$ and $I_{c x}, I_{c y}$, the distances $l_{j}$ and the road surface excitations $q_{i}(i=1 \div 4, j=1 \div 10)$.
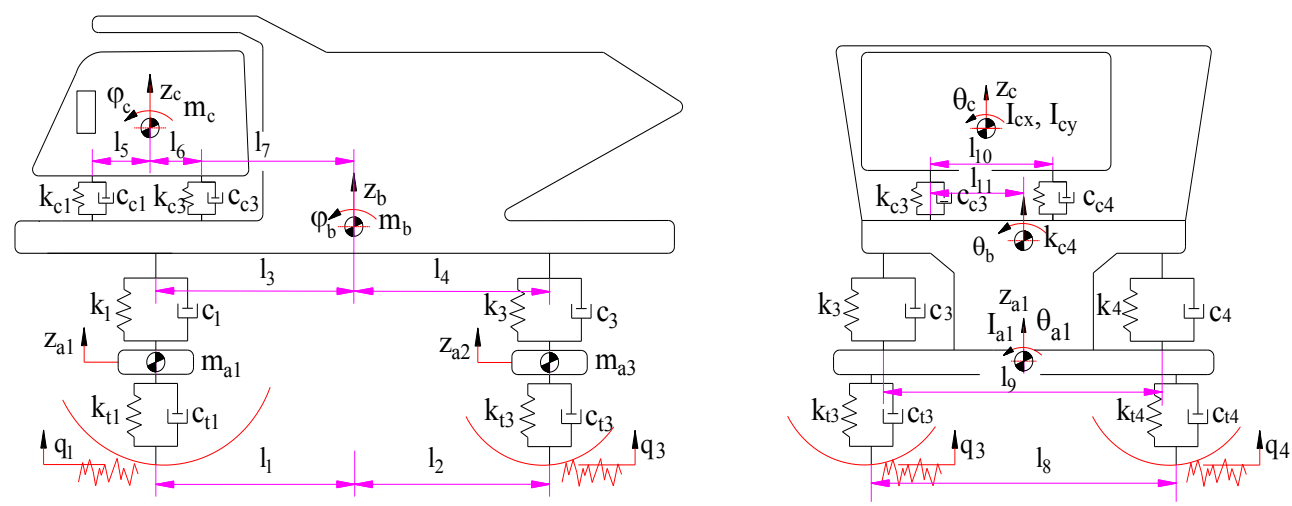

Fig 3. The nonlinear dynamic model of heavy truck

From the full-vehicle dynamic model of Fig.3, the motion equations of two axle masses, vehicle body mass and cab body mass are written using Newton's second law. The general dynamic differential equation for the 2-axle heavy truck is given by the following matrix form

$$
[M]\{\ddot{z}\}+[C]\{\dot{z}\}+[K]\{z\}=\left[C_{t}\right]\{\dot{q}\}+\left[K_{t}\right]\{q\}
$$

where $[\mathrm{M}],[\mathrm{C}]$, and $[\mathrm{K}]$ are the vehicle masses, damping coefficients, and stiffness coefficients matrices of the suspension systems; $\left[\mathrm{C}_{\mathrm{t}}\right]$ and $\left[\mathrm{K}_{\mathrm{t}}\right]$ are the damping coefficient and stiffness coefficient matrices of the tire systems; $\{\mathrm{z}\}$ is the vector of displacements; $\{\mathrm{q}\}$ is the vector of excitation of road surfaces.

\subsection{Random road surface excitation}

There are several methods for modeling road surface roughness according to different theories, such as the harmonic superposition method, the filtering white noise and AR method [13-17]. In this study, the random road surface roughness of random white noise is selected as excitation source waveform for vehicle suspension [16], the random road profile is produced by filtering the white noise using the following mathematical model of the road roughness

$$
\dot{q}(t)+2 \pi f_{0} q(t)=2 \pi n_{0} \sqrt{G_{q}\left(n_{0}\right) v} w(t)
$$

where, $G_{q}\left(n_{0}\right)$ is the road roughness coefficient which is defined for typical road classes from A to E according to ISO $8608(1995)$ [9], $\mathrm{n}_{0}$ is a reference spatial frequency which is equal to $0.1 \mathrm{~m}$; $\mathrm{v}$ is the speed of vehicle; $\mathrm{f}_{0}$ is a minimal boundary frequency with a value of $0.0628 \mathrm{~Hz} ; \mathrm{n}_{0}$ is a reference spatial frequency which is equal to $0.1 \mathrm{~m}$; w(t) is a white noise signal.

\section{Results and Discussion}

The general dynamic differential equation for the 2-axle heavy truck of Eq.(19) is solved by using Matlab/Simulink software with the reference heavy truck parameters [18]. The simulation results of the time domain acceleration responses of the vertical cabin, pitch and roll angles of the cabin $\left(a_{w z c b}, a_{w f c b}\right.$ and $\left.a_{w t c b}\right)$ with the novel HPSs compared to 
the traditional HPSs are shown in Fig 4 when vehicle moves on ISO class D road surface at vehicle speed of $50 \mathrm{~km} / \mathrm{h}$ and full load. From the simulation results show that the $\mathrm{a}_{\mathrm{zcb}}$, $\mathrm{a}_{\mathrm{fcb}}$ and $\mathrm{a}_{\mathrm{tcb}}$ of the novel HPSs respectively reduce in comparison with traditional HPSs. From the obtained results of Fig.4, we show that the peak amplitude values of $\mathrm{a}_{\mathrm{zcb}}$, $\mathrm{a}_{\mathrm{fcb}}$ and $\mathrm{a}_{\mathrm{tcb}}$ respectively reduce in comparison with traditional HPSs. The ride performance of the novel HPSs will continue to evaluate and compare to the traditional HPSs under different operating conditions.

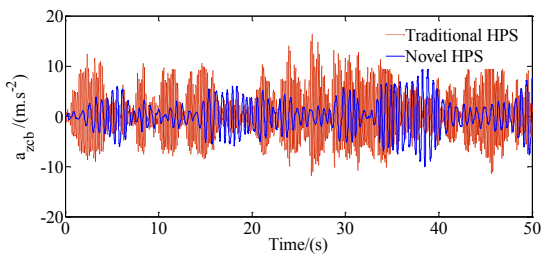

(a) The vertical cab

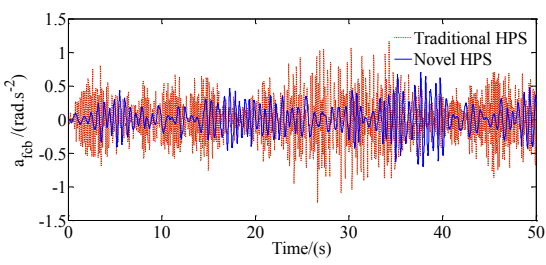

(b) The pitch angle of cab



(c) The roll angle of cab

Fig 4. Comparison results of the $\mathrm{a}_{\mathrm{zcb}}$, $\mathrm{a}_{\mathrm{fcb}}$ and $\mathrm{a}_{\mathrm{tcb}}$ with the novel HPSs and the traditional HPSs when vehicle moves on ISO class D road surface at vehicle speed of $50 \mathrm{~km} / \mathrm{h}$ and full load

\subsection{Different road surface conditions}

The vehicle moving on the different road surface conditions, five road surface conditions from ISO class A road surface to ISO class E road surface according to ISO 8068(1995) are selected for evaluation and comparison when vehicle moves at speed of $50 \mathrm{~km} / \mathrm{h}$ and full load. The values of the root mean square (RMS) acceleration responses the vertical $\mathrm{cab}$, pitch and roll angles of the cab of heavy truck $\left(\mathrm{a}_{\mathrm{wzcb}}, \mathrm{a}_{\mathrm{wfcb}}\right.$ and $\left.\mathrm{a}_{\mathrm{wtcb}}\right)$ based on the International Standard ISO 2631 1: 1997 which are determined through Eq. (21), as shown in Fig 5.

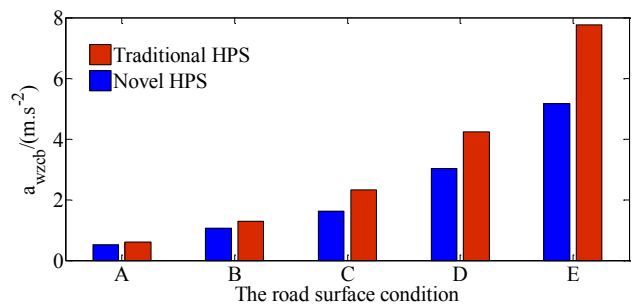

(a) The vertical cab

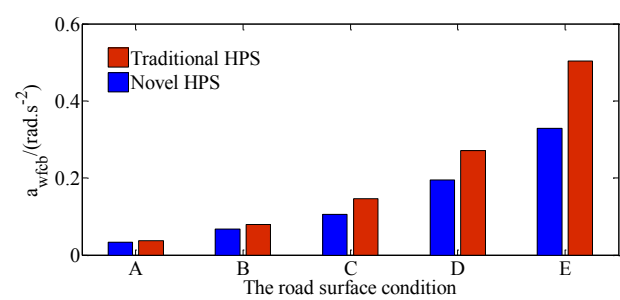

(b) The pitch angle of cab

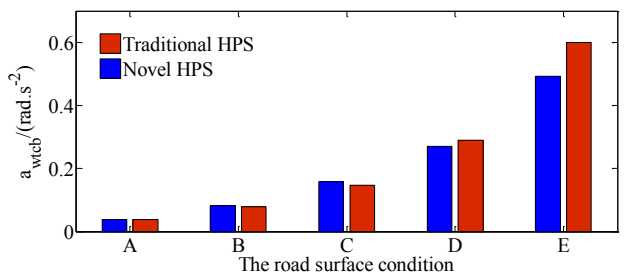

(c) The roll angle of cab

Fig 5. Comparison results of the $\mathrm{a}_{\mathrm{wzcb}}, \mathrm{a}_{\mathrm{wfcb}}$ and $\mathrm{a}_{\mathrm{wtcb}}$ values of two types of HPS systems under the different road surface conditions

From the results of Fig 5, it shows that the $\mathrm{a}_{\mathrm{wzcb}}, \mathrm{a}_{\mathrm{wfcb}}$ and $\mathrm{a}_{\mathrm{wtcb}}$ values of two types of HPS systems increase height very fast after the vehicle moves on poor and very poor road surface conditions, especially ISO class D road surface and ISO class E road surface. 
Vehicle ride comfort indicator is based on ISO 2631-1 (1997) [11], vibration evaluation based on the basic evaluation method, the RMS acceleration is determined as

$$
a_{w}=\left[\frac{1}{T} \int_{0}^{T} a^{2}(\mathrm{t}) \mathrm{dt}\right]^{\frac{1}{2}}
$$

where, $\mathrm{a}(\mathrm{t})$ is the weighted acceleration (translational and rotational) as a function of time, $\mathrm{m} / \mathrm{s}^{2} ; \mathrm{T}$ is the duration of the measurements.

The percent reduction of the $\mathrm{a}_{\mathrm{wzc}}, \mathrm{a}_{\mathrm{wfcb}}$ and $\mathrm{a}_{\mathrm{wtcb}}$ values with novel and traditional HPS systems are shown in Table 1 under the different road surface conditions. The calculation results in Table 1 show that vehicle ride comfort with novel HPSs is much better than traditional HPSs under the different road surface conditions.

Table 1. The percent reduction of the $\mathrm{a}_{\mathrm{wzcb}}, \mathrm{a}_{\mathrm{wfcb}}$ and $\mathrm{a}_{\mathrm{wtcb}}$ values with novel and traditional HPS systems under the different road surface conditions

\begin{tabular}{|c|c|c|c|c|c|}
\hline $\begin{array}{c}\text { Road surface } \\
\text { conditions }\end{array}$ & ISO class A & ISO class B & ISO class C & ISO class D & ISO class E \\
\hline $\mathrm{a}_{\text {wzcb }}$ & $14.95 \%$ & $17.89 \%$ & $30.34 \%$ & $28.27 \%$ & $33.52 \%$ \\
\hline $\mathrm{a}_{\mathrm{wfcb}}$ & $10.03 \%$ & $14.63 \%$ & $28.00 \%$ & $28.32 \%$ & $34.55 \%$ \\
\hline $\mathrm{a}_{\mathrm{wtcb}}$ & $-2.66 \%$ & $-2.52 \%$ & $-7.74 \%$ & $6.89 \%$ & $17.77 \%$ \\
\hline
\end{tabular}

\subsection{Different speed conditions}

The different vehicle speed conditions from $20 \mathrm{~km} / \mathrm{h}$ to $70 \mathrm{~km} / \mathrm{h}$ is used to compare with the novel and traditional HPS systems when vehicle moves on ISO class D road surface and full load. The $\mathrm{a}_{\mathrm{wzcb}}, \mathrm{a}_{\mathrm{wfcb}}$ and $\mathrm{a}_{\mathrm{wtcb}}$ values with the novel HPSs compared to the traditional HPSs at the different vehicle speeds are shown in Fig 6. From the results Fig 6, we show that the $\mathrm{a}_{\mathrm{wzcb}}, \mathrm{a}_{\mathrm{wfcb}}$ and $\mathrm{a}_{\mathrm{wtcb}}$ values with novel and traditional HPS systems respectively increase when the value of the vehicle speed increases. However, the growth rate of the $\mathrm{a}_{\mathrm{wzcb}}, \mathrm{a}_{\mathrm{wfcb}}$ and $\mathrm{a}_{\mathrm{wtcb}}$ values with the novel HPS is lower than that of traditional HPS when the value of the vehicle speed increases. The percent reduction of the $\mathrm{a}_{\mathrm{wzcb}}$, $\mathrm{a}_{\mathrm{wfcb}}$ and $a_{\text {wtcb }}$ values with the novel HPSs in comparison with the traditional HPSs at different speed conditions are show in Tab.2. From the results in Tab. 2, we show that the $a_{\text {wzcb }}, a_{\text {wfcb }}$ and $a_{\text {wcb }}$ values with the novel HPSs are much lower in comparison with traditional HPSs. The vehicle ride comfort with the novel HPSs has significantly improved in comparison with the traditional HPS at the different vehicle speeds.

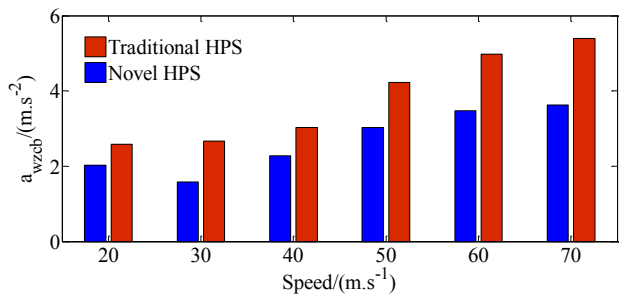

(a) The vertical cab

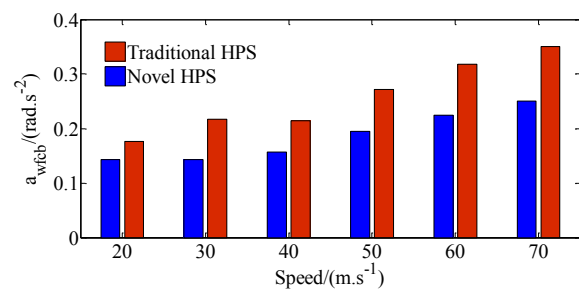

(b) The pitch angle of cab

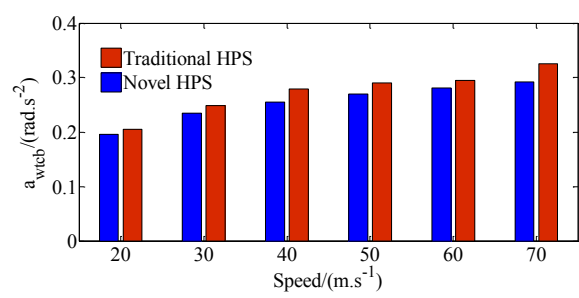

(c) The roll angle of cab

Fig 6. Comparison results of the $a_{w z c b}, a_{w f c b}$ and $a_{w t c b}$ values of two types of HPS systems at the different vehicle speeds

Table 2. The percent reduction of the $\mathrm{a}_{\mathrm{wzcb}}, \mathrm{a}_{\mathrm{wfcb}}$ and $\mathrm{a}_{\mathrm{wtcb}}$ values with novel and traditional HPS systems at the different vehicle speeds

\begin{tabular}{|c|c|c|c|c|c|c|}
\hline $\mathrm{v} /(\mathrm{km} / \mathrm{h})$ & $20(\mathrm{~km} / \mathrm{h})$ & $30(\mathrm{~km} / \mathrm{h})$ & $40(\mathrm{~km} / \mathrm{h})$ & $50(\mathrm{~km} / \mathrm{h})$ & $60(\mathrm{~km} / \mathrm{h})$ & $70(\mathrm{~km} / \mathrm{h})$ \\
\hline $\mathrm{a}_{\text {wzcb }}$ & $21.22 \%$ & $40.76 \%$ & $24.79 \%$ & $28.27 \%$ & $30.35 \%$ & $32.83 \%$ \\
\hline $\mathrm{a}_{\text {wfcb }}$ & $18.79 \%$ & $34.10 \%$ & $26.69 \%$ & $28.32 \%$ & $29.53 \%$ & $28.55 \%$ \\
\hline $\mathrm{a}_{\text {teta }}$ & $4.82 \%$ & $5.62 \%$ & $8.73 \%$ & $6.89 \%$ & $4.72 \%$ & $10.35 \%$ \\
\hline
\end{tabular}




\section{Conclusions}

In this study, a novel HPSs which was developed the traditional HPS by connecting a main air chamber and an auxiliary air chamber through the surge pipe was proposed as well as the mathematical models of traditional and novel HPS are established to determine their vertical forces. The ride performance of the novel HPSs was evaluated and compared to that of traditional HPSs based on a nonlinear dynamic model of heavy truck with 10 degrees of freedom (DOFs) under different operating conditions. Some conclusions could be drawn from the comparison and evaluation results: (1) The $\mathrm{a}_{\mathrm{wzcb}}, \mathrm{a}_{\mathrm{wfcb}}$ and $\mathrm{a}_{\mathrm{wtcb}}$ values with novel HPSs reduced by $28.27 \%, 28.32 \%$ and $6.89 \%$ in comparison with the traditional HPSs when vehicle moves on ISO class D road surface at speed of $50 \mathrm{~km} / \mathrm{h}$ and full load, (2) The $a_{w z c b}$, $a_{w f c b}$ and $a_{w t c b}$ values with the novel HPSs respectively reduced in comparison with traditional HPSs under the different road surface, and (3) The $a_{w z c b}, a_{w f c b}$ and $a_{w t c b}$ values with the novel HPSs respectively reduced in comparison with traditional HPSs at the different vehicle speeds.

\section{Acknowledgment}

The work described in this paper was supported by Thai Nguyen University (TNU), Thai Nguyen University of Technology (TNUT) for a scientific project (Code: DH2019-TN02 - 02).

\section{References}

1. L. Shang-hong et al, Research on Height Control Algorithm for Hydro-Pneumatic Suspension System Based on Model Predictive Control, International Industrial Informatics and Computer Engineering Conference, IIICEC (2015)

2. Sh. Han et al, Shock and Vibration, Hidawi, 2017

3. B. Qin et al, Applied Sciences, MDPI, 2021

4. Zh. Sang et al., Advances in Mechanical Engineering 9, 5 (2017)

5. F. Saglam, Y. Samim Unlusoy, Analysis of Interconnected Hydro-Pneumatic Suspension System for Load Sharing among Heavy Vehicle Axles, Proceedings of the 3rd International Conference on Control, Dynamic Systems, and Robotics, Ottawa, Canada (2016)

6. H. Zhao et al., Advances in Mechanical Engineering 10, 11 (2018)

7. J. Zhang et al., Mathematical Problems in Engineering (2015)

8. Hengmin Qi, Y., Zhang et al., Proceedings of the Institution of Mechanical Engineers, Part D: Journal of Automobile Engineering (2019)

9. ISO 8608, Mechanical Vibration-Road Surface Profiles-Reporting of Measured Data. International Organization for Standardization (1995)

10. Malin Presthus, Derivation of air spring model parameters for train simulation, Master's Thesis, Department of Applied Physics and Mechanical Engineering Division of Fluid Mechanic (2002)

11. ISO 2631-1, Mechanical Vibration and Shock-Evaluation of Human Exposure to Whole-Body Vibration, Part I: General Requirements. ISO, 1997.

12. W. Yue et al., World Journal of Engineering and Technology (2017)

13. L.X. Long et al., International Journal of Mechanical Engineering and Technology 9 (2019)

14. V.Q. Le, Vibroengineering Procedia 14 (2017)

15. V.Q. Le, V.C. Bui et al., Adva. In Engi. Re and App. (2019)

16. V.Q. Le et al., Vibroengineering PROCEDIA 16 (2017)

17. L.X. Long, L.V. Quynh, Vibroengineering Procedia 21 (2018)

18. L.X. Long, Science research topic: Thai Nguyen University. Thai Nguyen, Vietnam (2021) 